\title{
Bridging Bridges
}

Authors: Julie Letchford and Keith Brown. University of Bath

Background: Integration of pharmaceutical science with clinical practice is crucial to both the professional reaccreditation of our degree programme and to the pharmacy profession. This pilot aimed to identify how one subject area, namely microbiology, is cross-linked with other units of the pharmacy degree programme taught at one UK School of Pharmacy.

Method: Two final year undergraduate pharmacy students were recruited to generate learning materials intended for staff and students, which highlight how microbiology relates to both science and practice. Students were encouraged to use their own initiative and creativity by working independently of staff and kept a reflective log throughout the project. They began by producing a comprehensive mind map summarising how microbiology is linked vertically and horizontally with other units throughout the course (Fig 1) and then used this information to produce a learning resource for year one students.

Results: Students used Camtasia to produce a You-Tube video animation demonstrating how microbiology is integrated into year 1 of the pharmacy programme. Resources developed for this project are of benefit to staff, students and their peers; staff were able to exploit student perceptions of unit integration, and

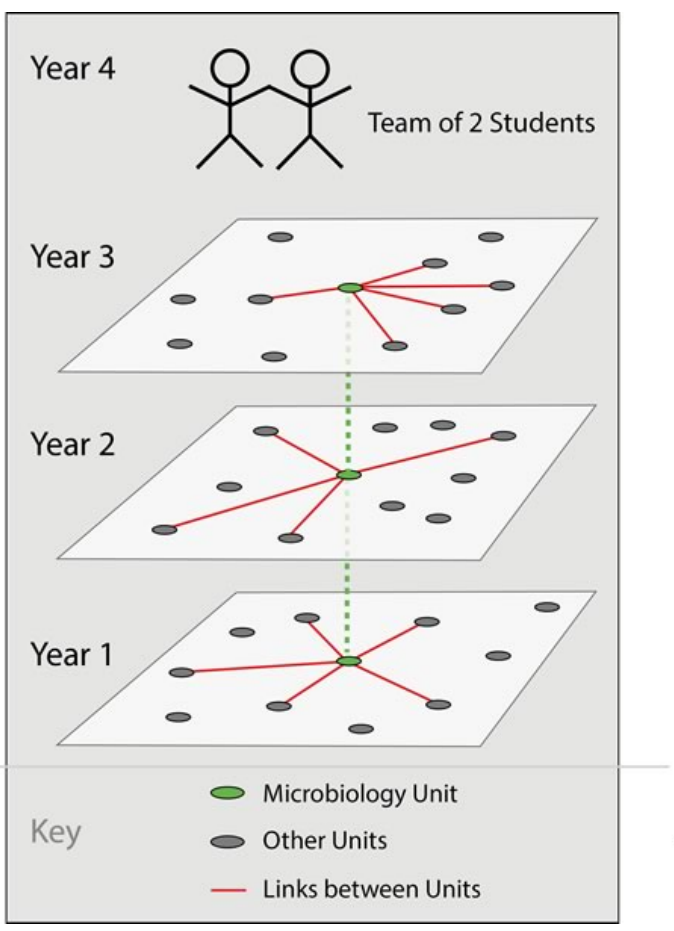

Figure 1-framework used to create mind-map students recruited for the task improved their teamwork, digital presentation skills and employability. Furthermore, the animation was evaluated: The results indicate that it was well received by Year 1 students who stated that it provided them with a better understanding of the importance of microbiology, and how it fits with other units of the undergraduate MPharm curriculum.

Conclusion: The project demonstrates the power of student partnerships in promoting personal development and student learning. It also illustrates how an improved knowledge of unit integration benefits existing students, prospective students and academic staff. It is anticipated that this type of project can be applied to other units in the future in order to better illustrate the integration of science and practice throughout the MPharm curriculum. 